\title{
Collateral Secured Loans in a Monetary Economy
}

\author{
Leo Ferraris* \\ Universidad Carlos III de Madrid
}

\author{
Makoto Watanabe ${ }^{\dagger}$ \\ Universidad Carlos III de Madrid
}

January 29, 2007

\begin{abstract}
Durable assets are widely used as collateral to secure the repayment of debt. This paper presents a monetary search model where durable assets can serve as a guarantee to repay consumption loans. In our economy, consumers can obtain loans from banks using their durable capital assets as collateral. In case repayment doesn't happen the bank can seize the amount committed as collateral. We prove the existence, uniqueness and we characterize steady state monetary equilibria with collateralized bank credit. We show that collateralized credit can be an important channel through which monetary factors can affect real variables, and that the effect of monetary growth on capital accumulation depends critically on the relative risk aversion of agents and the relative scarcity of durable capital goods in the economy.
\end{abstract}

\section{Introduction}

Durable assets play a dual role as investment goods and as collateral to secure loans ${ }^{1}$. Their availability can affect consumption and investment decisions, limiting the access of households and firms to credit: both the household sector and the business sector extensively rely on durable assets, often real estate ${ }^{2}$, to obtain loans which - in the absence of collateral- would not be granted. The accumulation of durable assets serving as collateral, changes in response to the tightness of the credit market, which in turn responds to monetary factors. The objective of the present paper is to analyze the effect of monetary growth on durable assets accumulation in a monetary micro-founded economy with loans secured by such assets.

The need for collateral emerges naturally in the model because of the impossibility to monitor borrowers and of limited enforcement. The environment is a version of Lagos and Wright (2005) - augmented with loans and a durable asset ${ }^{3}$. In their model, agents' anonymity and limited enforcement are the building blocks of a fundamental theory of money, but make it hard to

*Department of Economics, Universidad Carlos III de Madrid, Calle Madrid 126, 28903 Getafe Madrid, SPAIN. Email: lferrari@eco.uc3m.es, Tel.: +34-91-624-9619, Fax: +34-91624-9329.

$\dagger$ Department of Economics, Universidad Carlos III de Madrid, Calle Madrid 126, 28903 Getafe Madrid, SPAIN. Email: mwatanab@eco.uc3m.es, Tel.: +34-91624-9331, Fax: +34-91624-9329.

${ }^{1}$ Collateral secured loans account for a high percentage of all loans. According to the last Federal Reserve Survey of Terms of Business Lending (released September 19, 2006), in the US, the value of all commercial and industrial loans secured by collateral made by US banks accounted for $46.9 \%$ of the total value of loans.

${ }^{2}$ In 2004, 47.9 percent of the households in the US had home-secured debt, whereby their house was used as a guarantee of repayment (Survey of Consumer Finances, Board of Governors of the Federal Reserve System, 2004).

${ }^{3}$ Berentsen, Camera and Waller (2006) introduce borrowing and Aruoba and Wright (2003) capital accumulation in the Lagos and Wright model. The present model has features in common with both papers. We discuss the relationship to these and other models at the end of Section 3. 
sustain equilibria with borrowing. In our model, we exploit these very features to generate a role for consumption loans collateralized by a durable asset.

Here is an informal description of the model economy. Time continues for ever and each period consists of two sub-periods, day and night. Exchange happens during each sub-period but in different ways. During the day, exchange is hindered by frictions which motivate the use of money. During the night, trade happens in a frictionless market where a durable good is produced and exchanged. We will refer to it simply as capital. In the economy a competitive banking system operates, accepting deposits and making loans during the day, to be repaid during the night. Agents are anonymous and cannot be monitored, and enforcement is limited. Relative to individuals in the economy, banks do not have a superior monitoring or enforcement technology, but they have a superior ability to seize the capital asset. Agents needing a loan sign a contract with a bank, stipulating an amount of money, an interest payment, an amount of capital to commit as collateral and the obligation to repay during the following night. In case repayment doesn't happen the bank can seize the collateral. Agents are thus subject to a borrowing constraint of the form studied by Kiyotaki and Moore (1997) in a non-monetary economy.

In our economy, banks perform a beneficial role, allowing the transfer of funds - which would remain otherwise idle- to agents in need of a loan. The capital asset, acting as collateral, allows to overcome the difficulties encountered by banks in enforcing the repayment of loans. Accumulating capital - over and above what it would be optimal from a purely productive point of view- can, when capital is relatively scarce, help agents to relax their borrowing constraint. In turn, monetary growth affects the tightness of the borrowing constraint and through this channel the accumulation of capital. Two situations can arise as steady state monetary equilibria with collateralized bank credit. One where the borrowing constraint is not binding and capital accumulation is at its optimal level ${ }^{4}$ and one where the borrowing constraint is binding and capital accumulation is above its optimal level. In turn, the borrowing constraint is more likely to be binding if capital is relatively scarce ${ }^{5}$. In the former situation, capital accumulation is unaffected by monetary factors. In the latter, more interesting, situation, the effect of monetary growth on capital accumulation can differ substantially depending on the relative risk aversion of agents. When relative risk aversion is lower than one, capital accumulation is hump-shaped in the inflation rate. The intuition is as follows. If relative risk aversion is lower than one, the demand for day-time consumption - which is always decreasing in the inflation rate- is more than unit elastic in inflation. When capital is relatively scarce, at low inflation rates, agents accumulate as much of it as possible in order to relax their borrowing constraint. As inflation grows they reduce their demand for day-time consumption more than one to one with inflation and this reduces their need for the capital as collateral for loans. Eventually capital accumulation reverts to its First Best level where it is unaffected by inflation. When relative risk aversion is one, demand is unit elastic in inflation and if capital is scarce, at low inflation rates agents over-accumulate it. As inflation grows, they reduce day-time consumption one to one with the increase in inflation, keeping capital unchanged. When relative risk aversion is higher than one, demand is less than unit elastic in inflation. If capital is abundant, for low inflation rates, agents have no use for extra capital, but as inflation grows agents reduce their demand less than one to one with inflation. This induces them to accumulate more capital in order to relax a tighter credit constraint. When the capital is scarce, agents start over-accumulating it even at very low levels of inflation.

Section 2 presents the model and derives the equilibrium. Section 3 concludes.

\footnotetext{
${ }^{4}$ The optimal level in our model coincides with the First Best level for capital accumulation.

${ }^{5}$ As a measure of scarcity or abundance we use the ratio of capital to consumption at First Best. In terms of the fundamentals, the First Best capital level is abundant relative to the First Best consumption level if the discount rate is high or capital is very productive.
} 


\section{The Model}

\subsection{The Environment}

The model is built on the divisible money framework developed in Lagos and Wright (2005). Time is discrete and continues forever. There is a $[0,1]$ continuum of infinitely-lived agents. Each period is divided into two sub-periods, called day and night. A perfectly competitive market opens in each sub-period. Economic activity differs between day and night. During the day, agents can trade a perishable consumption good and face randomness in their preferences and production possibilities. An agent is a buyer with probability $\sigma$ in which case he wants to consume but cannot produce, whereas an agent is a seller with probability $1-\sigma$ in which case he is able to produce but does not wish to consume. ${ }^{6}$ During the night, agents can trade a durable good that can be used for consumption or investment. In contrast to the first subperiod, there is no randomness in the second sub-period, and all agents can produce and consume simultaneously.

There is an intrinsically worthless good, which is perfectly divisible and storable, called fiat money. We assume that all goods trades are anonymous and so trading histories of agents are private knowledge. Combined with the presence of randomness described above, anonymity in goods trades motivates an essential role of money: sellers must receive money for immediate compensation of their products. The supply of fiat money is controlled by the government so that $M_{+1}=(1+\pi) M$, where $M$ denotes the money stock at a given period, +1 the following period, and $\pi$ the growth rate of money which we assume to be constant. New money is injected, or withdrawn, at the start of each period by lump-sum transfers or taxes which we denote by $t$. Both buyers and sellers receive these transfers equally.

Consumption during the day yields utility $u\left(q_{b}\right)$ that, we assume, satisfies $u^{\prime}(\cdot)>0, u^{\prime \prime}(\cdot)<$ $0, u^{\prime}(0)=\infty$, and $u^{\prime}(\infty)=0$, where $q_{b}$ represents the amount of daytime-consumption. Production during the day requires utility $\operatorname{cost} c\left(q_{s}\right)=q_{s}$, where $q_{s}$ represents the amount of daytimeproduction. Agents obtain utility from $x$ - i.e. consumption of durable goods- during the night, given by $U(x)=x \cdot{ }^{7}$ Simultaneously, agents can produce these goods using capital $k$. We assume that one's capital is not mobile so that it cannot be carried into the day market. Agents have an access to a production technology $f(k)$ that satisfies $f^{\prime}(\cdot)>0, f^{\prime \prime}(\cdot)<0, f^{\prime}(0)=\infty$, and $f^{\prime}(\infty)=0$. In what follows, we study situations where capital is sustainable over time. That is, we study the range of capital satisfying $0 \leq k \leq k^{\prime}$ where $k^{\prime}$ defines the the maximal sustainable level of capital and is a solution to $f\left(k^{\prime}\right)=k^{\prime}$. Capital depreciates at a rate $\delta \in(0,1)$. Agents discount future payoffs at a rate $\beta \in(0,1)$ across periods, but we assume for simplicity that there is no discounting between two sub-periods.

There exist private competitive banks, accepting deposits and issuing loans. Each period, before entering the day market, but after having discovered whether they are going to be buyers or sellers, agents can contact a bank, in order to deposit their money or obtain a loan denoted $d, l$, respectively. Loans are repaid and deposits are withdrawn during the night of the same period. As in goods trades, agents are anonymous in financial transactions and their credit histories are private knowledge. Banks do not have technologies that allow them to punish borrowers by excluding them from future financial transactions in case of default. The debt repayment, however, can be enforced by using collateral. Should they find themselves in need of a loan for daytime consumption, individual agents can commit part or all of their physical capital as a guarantee of repayment. The bank has the right to seize the collateral when the loan is not paid back, and thus voluntary repayment can be ensured. ${ }^{8}$ Assuming that output is not verifiable and

\footnotetext{
${ }^{6}$ This formulation is adopted also in Berentsen, Camera and Waller (2006), Lagos and Rocheteau (2005), and Rocheteau and Wright (2005).

${ }^{7} \mathrm{As}$ is common in the divisible money models, the linear (or quasi linear) preferences of nightime consumption is a device to make the distribution of money holdings degenerate at the beginning of a period, which in turn makes the model highly tractable.

${ }^{8}$ See Kiyotaki and Moore (1997) for an extensive discussion on the use of capital as collateral.
} 
capital is not mobile from the location where it was produced, we focus our attention on credit deals where only capital can serve as collateral. Assuming further that individual agents have inferior skills in verifying and seizing assets relative to banks implies that promises backed by collateralized capital cannot circulate as credit among individuals during the day. Hence, fiat money is still used as a medium of exchange in goods trades.

\subsection{The Social Optimum}

We shall begin with the first best solution. The social planner treats agents symmetrically and maximizes average expected utility. The planner's problem describes:

$$
\begin{gathered}
J(k)=\max _{q_{b}, q_{s}, k_{+1}, x}\left[\sigma u\left(q_{b}\right)-(1-\sigma) q_{s}+x+\beta J_{+1}\left(k_{+1}\right)\right] \\
\text { s.t. } q_{b}=(1-\sigma) q_{s}, \\
x=F(k)-k_{+1},
\end{gathered}
$$

where $F(k) \equiv(1-\delta) k+f(k)$. Equation (1) is the feasibility constraint for daytime consumption, and equation (2) is the feasibility constraint for nighttime consumption. At night, the amount of durable goods available for consumption, $x$, is provided by the total of the undepreciated and the newly produced, $F(k)$, minus the amount carried into the next period, $k_{+1}$.

The optimal solution in steady state, denoted by $q_{b}^{*}, q_{s}^{*}, k^{*}, x^{*}$, satisfy the following first order conditions:

$$
\begin{aligned}
u^{\prime}\left(q_{b}^{*}\right) & =1, \\
\beta F^{\prime}\left(k^{*}\right) & =1,
\end{aligned}
$$

and the feasibility constraints $(1),(2): q_{s}^{*}=\frac{\sigma}{1-\sigma} q_{b}^{*} ; x^{*}=F\left(k^{*}\right)-k^{*}$. At the optimum, the marginal utility of consumption is set equal to the marginal cost of production during the day, while the marginal utility of consuming one unit of durable goods $(=1)$ at a given night is set equal to the discounted value of the marginal returns, accruing at the following night, from accumulating an extra unit of capital $\left(=\beta F^{\prime}\left(k^{*}\right)\right)$.

\subsection{Steady-state equilibrium}

In what follows, we construct symmetric and steady-state equilibria where all agents take identical strategies and all real variables are constant over time. Before proceeding, it is worth mentioning the characteristics of credit deals in such equilibria. First, given our environment, it is straightforward to show that buyers will not deposit their money because they will be able to use it for consumption, while sellers will not want to borrow money because they have no use of it at day. Hence, in the credit transactions with banks buyers are borrowers while sellers are depositors each day. Second, because their capital is the only asset that can be used as collateral, individual buyers face an upper bound on the amount of borrowing if they wish to consume beyond their budget. Formally, if a buyer holds capital $k$ at a given period, then he can borrow $l$ in total at that day, as long as it satisfies

$$
\phi(1+i) l \leq k,
$$

where $\phi$ is the value of a unit of money and $i$ the nominal interest rate (which is endogenous and determined on the competitive credit market). The L.H.S. of the above inequality represents the real-valued repayment of his debt. An important point is that the property of equilibrium depends on whether the credit constraint (5) is binding or not. When the constraint is binding, one prefers to borrow up to the maximum and so his capital holdings play dual roles, that is, one is to determine the marginal productivity of nighttime production and the other is to determine the budget set of daytime consumption as a buyer. The latter role of capital holdings is absent when the constraint is not binding. 
Night market We work backward and start with the night market. As already mentioned, during the night, agents consume, produce, and trade durable goods, and clear the credit balances they have had with banks during the day. The expected value of an agent entering the night market at a given period with holding $m$ of money, $l$ of loans, $d$ of deposits and $k$ of capital, denoted by $W(m, l, d, k)$, satisfies

$$
\begin{array}{ll} 
& W(m, l, d, k)=\max _{x, m_{+1}, k_{+1}}\left[x+\beta V\left(m_{+1}, k_{+1}\right)\right] \\
\text { s.t. } & x+k_{+1}+\phi m_{+1}+\phi(1+i) l=F(k)+\phi m+\phi(1+i) d,
\end{array}
$$

where $V\left(m_{+1}, k_{+1}\right)$ denotes the expected value of operating in the next day market with holding $m_{+1}$ money and $k_{+1}$ capital. The nominal price in the night market is normalized by 1 , and so $\phi$ represents the relative price of money. If the agent has been a buyer during the day, then $d=0$ and he consumes $x$ units and repay $(1+i) l$ units of money by producing and selling $F(k)$ units and using $m$ units of money he initially holds. If the agent has been a seller during the day, then $l=0$ and he consumes $x$ units by producing and selling $F(k)$ units and using $m$ units of money he initial holds and $(1+i) d$ units of monetary repayment of his deposit. Note that banks are competitive so the interest rate is the same across loans and deposits. After the night market is closed, the agent carries forward $m_{+1}$ money and $k_{+1}$ capital to the following period.

Solving the budget constraint (6) for $x$ and substituting it into the value function, the first order conditions with respect to $m_{+1}$ and $k_{+1}$ are respectively derived as follows.

$$
\begin{aligned}
\beta V_{m}\left(m_{+1}, k_{+1}\right) & =\phi, \\
\beta V_{k}\left(m_{+1}, k_{+1}\right) & =1,
\end{aligned}
$$

where $V_{i} \equiv \frac{\partial V(m, k)}{\partial i}$ for $i=m, k$. It is clear from these expressions that the $m_{+1}, k_{+1}$ are determined independently of both $m, k$, and hence all agents hold the same amount of money and capital at the beginning of any given day market. ${ }^{9}$

Finally, the envelope conditions -where $W_{i} \equiv \frac{\partial W(m, l, d, k)}{\partial i}$ for $i=m, l, d, k-$ are:

$$
\begin{aligned}
W_{m} & =\phi, \\
W_{l} & =-\phi(1+i), \\
W_{d} & =\phi(1+i), \\
W_{k} & =F^{\prime}(k) .
\end{aligned}
$$

Day market Agents during the day either consume and borrow as buyers or produce and deposit as sellers. All agents start any given period with the same amount of money and capital holdings. The expected value of an agent, $V(m, k)$, entering the day market with $m$ money and $k$ capital, satisfies:

$$
\begin{aligned}
V(m, k)= & \sigma\left\{\begin{array}{c}
\max _{q_{b}, l}\left[u\left(q_{b}\right)+W\left(m+t+l-p q_{b}, l, d, k\right)\right] \\
\text { s.t. } p q_{b} \leq m+t+l \\
\phi(1+i) l \leq k
\end{array}\right\}+ \\
& +(1-\sigma)\left\{\begin{array}{c}
\max _{q_{s}, d}\left[-q_{s}+W\left(m+t-d+p q_{s}, l, d, k\right)\right] \\
\text { s.t. } d \leq m+t
\end{array}\right\},
\end{aligned}
$$

where $p$ is the nominal price of daytime goods. If the agent happens to be a buyer with probability $\sigma$, then he spends $p q_{b}$ money for his consumption, which is no greater than his initial money $m$

\footnotetext{
${ }^{9}$ Note, however, that the nighttime consumption $x$ (determined to satisfy equation (6)) differs across agents depending on the credit status and the initial money holding at the beginning of night. See the Appendix for more details.
} 
plus the monetary transfer $t$ and a loan $l$ that he takes out from a bank. His loan $l$ is subject to the credit constraint given the amount of capital $k$ he has accumulated from the previous night. If the agent happens to be a seller with probability $1-\sigma$, then he produces $q_{s}$ units and obtains $p q_{s}$ money. At the same time, he deposits $d$ money which is no greater than his initial money $m$ plus the monetary transfer $t$. The agent then moves on to the night market with the remaining money which differs across these events.

The first order conditions for the day market choices are:

$$
\begin{aligned}
p W_{m}+p \lambda & =u^{\prime}\left(q_{b}\right) \\
p W_{m} & =1 \\
W_{l}+W_{m} & =\gamma \phi(1+i)-\lambda, \\
W_{d}-W_{m} & =\rho,
\end{aligned}
$$

where $\lambda \geq 0$ is the multiplier of the buyer's budget constraint, $\gamma \geq 0$ the multiplier of the credit constraint, $\rho \geq 0$ the multiplier of the seller's deposit constraint.

It is worth mentioning some properties of the optimal choices in the day-market that are immediate from the above conditions. First, equations (9), (14) imply:

$$
\frac{1}{p}=\phi
$$

That is, the seller produces up to the point where the marginal costs of production per unit of money at day $(=1 / p)$ and at night $(=\phi)$ are equal.

Second, equations (9), (10), (13), (15), (17) yield

$$
u^{\prime}\left(q_{b}\right)=1+\frac{\lambda}{\phi}=(1+\gamma)(1+i) .
$$

The first equality implies that, given $\phi>0$, the complementary slackness condition for the buyer's budget constraint requires

$$
\left[u^{\prime}\left(q_{b}\right)-1\right]\left[m+t+l-p q_{b}\right]=0 .
$$

Similarly, the second equality implies that the complementary slackness condition for the credit constraint requires

$$
\left[u^{\prime}\left(q_{b}\right)-(1+i)\right][k-\phi(1+i) l]=0 .
$$

Observe that for $\gamma=0$, we have $u^{\prime}\left(q_{b}\right)=1+i$ and $k \geq \phi(1+i) l$ in which case the buyer borrows up to the point where the marginal benefit of an extra unit of loan $\left(=u^{\prime}\left(q_{b}\right)\right)$ equals the marginal cost $(=1+i)$. For $\gamma>0$, we have $k=\phi(1+i) l$ and $u^{\prime}\left(q_{b}\right)>1+i$ in which case the credit constraint is binding and the marginal benefit of a loan exceeds its marginal cost.

Third, equations (9), (10), (16) yield $\phi i=\rho$, hence the complementary slackness condition for the seller's deposit constraint requires, given $\phi>0$, that

$$
i[m+t-d]=0 .
$$

For $\rho=0$, we must have $d \leq m+t$ and $i=0$ in which case the seller is indifferent between depositing and holding his money with him. For $\rho>0$, we must have $d=m+t$ and $i>0$ in which case the seller has a strict incentive to deposit his money. In what follows, we assume that sellers deposit their money if indifferent, so $d=m+t$ for any $i \geq 0$.

Euler equations We now derive the Euler equations. Using equations (7), (9), (11), (13), (16) and the envelope condition, $V_{m}(m, k)=W_{m}+\sigma \lambda+(1-\sigma) \rho$, we obtain the Euler equation for money holdings:

$$
\phi=\beta \phi_{+1}\left[\sigma u^{\prime}\left(q_{b,+1}\right)+(1-\sigma)\left(1+i_{+1}\right)\right] .
$$


In the above equation, the marginal cost of obtaining an extra unit of money today $(=\phi)$ equals the discounted value of its expected marginal benefit obtained tomorrow. The marginal value of money is the marginal utility $\left(=u^{\prime}(\cdot)\right)$ when a buyer, or an interest payment of an extra unit of deposit $(=1+i)$ when a seller.

Similarly, using equations (8), (10), (12), (13), (15), (17) and the envelope condition, $V_{k}(m, k)=$ $W_{k}+\sigma \gamma$, we obtain the Euler equation for capital holdings:

$$
1=\beta\left[\sigma\left(\frac{u^{\prime}\left(q_{b,+1}\right)}{1+i_{+1}}-1\right)+F^{\prime}\left(k_{+1}\right)\right],
$$

where the marginal cost of accumulating an extra unit of capital today $(=1)$ equals the discounted value of its expected marginal benefit accruing tomorrow. The benefit of capital consists of two parts. On the one hand, the agent obtains the marginal returns $\left(=F^{\prime}(\cdot)\right)$ for the nighttime production. On the other hand, if the agent turns out to be a buyer, then he will be able to borrow an extra amount of funds equal to $\frac{1}{1+i_{+1}}$, since the value of a unit of capital will have to be enough to repay the gross interest payment of his loan. This will generate the net benefit of an additional loan given by the marginal utility of daytime consumption $\left(=u^{\prime}(\cdot)\right)$ minus the repayment cost $\left(=1+i_{+1}\right)$.

It is important to observe from the Euler equation (23) that the latter benefit of capital holdings (to increase the daytime consumption) generates a possibility that the growth rate of the value of money, $\phi_{+1} / \phi$, affects the capital holding decision by individuals. To see this point, consider a case in which $u^{\prime}\left(q_{b}\right)=1+i$ holds and so the credit constraint (5) is slack. In this case, the Euler condition (23) reduces to $1=\beta F^{\prime}\left(k_{+1}\right)$ where the level of capital holdings by individuals is determined independently of the money growth rate. When $u^{\prime}\left(q_{b}\right)>1+i$, however, the credit constraint is binding and the level of consumption and capital holdings are jointly determined by equations (22), (23). Hence, the binding credit constraint in our model provides a channel through which monetary policy, determining $\phi_{+1} / \phi$, can affect the individual decisions on both consumption and capital investment.

Market-clearing conditions So far, we have described the decision problems of a given individual agent taking the market prices $p, \phi, i$ as given. Each of the prices are determined by the respective market-clearing condition. These are the last requirements for symmetric and steady-state equilibria in our model. For the daytime goods, since all buyers buy $q_{b}$ units and all sellers sell $q_{s}$ units at any given period, the day-market clearing condition is given by

$$
\sigma q_{b}=(1-\sigma) q_{s} .
$$

For the nighttime goods, note that the level of nighttime consumption is bound to differ across agents depending on their daytime activity, while the level of capital holdings is not. Hence, the night-market clearing condition is given by

$$
X=F(k)-k_{+1} .
$$

where $X$ denotes the aggregate nighttime consumption which can be reduced to an expression with $x$ satisfying equation (6) averaged over buyers with $\sigma$ and sellers with $1-\sigma{ }^{10}$

For the loans and deposits, all the credit deals are made through the competitive banks. Note that given the presence of the credit constraint, it is possible that the interest rate $i \geq 0$ does not adjust to yield the demand-supply balancing. Hence, if there is excess supply in the credit market when $i=0$, we assume that the banks can hold voluntary reserves. This is consistent with our earlier assumption that sellers when indifferent always deposit their money holdings. Given this possibility, the credit-market clearing condition becomes

$$
\sigma l=(1-\sigma)(1-\mu) d
$$

where $\mu \in[0,1]$ represents the rate of bank reserves.

\footnotetext{
${ }^{10}$ See the Appendix for more details.
} 
Existence, uniqueness and characterization of steady-state equilibrium We now solve for equilibrium. We focus on steady-state equilibria where the aggregate real money supply, given by $\phi M$, is constant over time. So, we have $\frac{\phi_{+1}}{\phi}=\frac{1}{1+\pi}\left(\right.$ as $\left.M_{+1} / M=1 / 1+\pi\right)$. Further, denoting by $\tau$ the rate of government transfer, we have $t=\tau M_{-1}$ and $(1+\tau) M_{-1}=M=(1+\pi) M_{-1}$, thereby the value of money decreases at a rate equal to the gross rate at which the government injects money into the economy. Below, we consider policies where $1+\pi \geq \beta$, and when $1+\pi=\beta$ (which is the Friedman rule) we only consider the limiting equilibrium as $1+\pi \rightarrow \beta$.

Definition 1 A symmetric steady-state monetary equilibrium with credit defines a set of prices, $p, \phi>0, i, \geq 0$, and quantities, $q_{b}, q_{s}, x, d, l, k>0, \mu \geq 0$ that satisfies the budget constraint (6), the first order conditions (and the Euler equations) (17), (22), (23), the complementary slackness conditions (19), (20), (21), and the market-clearing conditions (24), (25), (26), where identical agents take identical strategies and all real variables are constant over time.

Any steady state equilibrium requires $x>0$ for all agents, although we have not imposed it. In order to guarantee this, we assume

$$
F\left(k^{*}\right)>q_{b}^{*}+\max \left\{k^{*},(1-\sigma) q_{b}^{*}\right\},
$$

where $q_{b}^{*}, k^{*}$ are the first best level of consumption and capital satisfying equations (3), (4). This inequality in turn requires an appropriate scaling of the production (or the utility) function.

To solve for equilibrium, the following lemma provides a useful guideline.

Lemma 1 If an equilibrium given in Definition 1 exists for $1+\pi>\beta$, then we must have $u^{\prime}\left(q_{b}\right)>1$ when $i=0$, and hence the credit constraint (5) must be binding, $k=\phi l$. Further, the budget constraint is binding, $p q_{b}=d+l$, for any $i \geq 0$ and $1+\pi>\beta$.

Proof. Equations (18) imply $u^{\prime}\left(q_{b}\right)=1+\frac{\lambda}{\phi}=1+\gamma$ for $i=0$. If $\lambda=\gamma=0$ when $i=0$, then $u^{\prime}\left(q_{b}\right)=1$. However, this implies the Euler equation (22) requires $1+\pi=\phi / \phi_{+}=\beta$. Hence, we must have $\lambda, \gamma>0$ and hence $u^{\prime}\left(q_{b}\right)>1$ for $r=0$ and $1+\pi>\beta$. Given this result, the second claim in the lemma is immediate from noting that the complementary slackness condition (20) requires $u^{\prime}\left(q_{b}\right) \geq 1+i$, and hence that $u^{\prime}\left(q_{b}\right)>1$ for any $i \geq 0$.

Lemma 1 shows that the equilibrium daytime consumption $q_{b}$ is determined by the credit constraint (5) and suggests there are three cases for equilibrium: [1] an equilibrium without binding credit-constraint and with $i>0 ;$ [2] an equilibrium with binding credit-constraint and $i>0 ;[3]$ an equilibrium with binding credit-constraint and $i=0$. In the last two cases monetary policies can impact on capital accumulations while in the first case they cannot. Note also that in the last case, banks hold the non-zero excess supply present in the credit market as voluntary reserves - i.e. $\mu>0-$, while in the first two cases $\mu=0$. In fact at a positive interest rate, the holding of reserves couldn't be part of an equilibrium given the competitive nature of the banking system, but at a zero interest rate banks can - and will- hold non-negative reserves in equilibrium. In the following proposition, we show that either type of equilibrium can emerge, depending on the coefficient of risk aversion, denoted by $\alpha \equiv-\frac{u^{\prime \prime}\left(q_{b}\right)}{u^{\prime}\left(q_{b}\right)} q_{b}$, and on the first best level of capital $k^{*}=F^{\prime-1}(1 / \beta)$ relative to $\sigma$ and $q_{b}^{*}=u^{\prime-1}(1)$.

Proposition 1 1. Suppose $\alpha<1$. If $k^{*} \geq(1-\sigma) q_{b}^{*}$, there is a unique equilibrium with unconstrained credit for any $\pi \in(\beta-1, \infty)$. If $k^{*}<(1-\sigma) q_{b}^{*}$, there exist two critical levels of inflation rate, $\hat{\pi}>\underline{\pi} \in(\beta-1, \infty)$, such that given $\lim _{q_{b} \rightarrow 0} u^{\prime}\left(q_{b}\right) q_{b}<k^{*} /(1-\sigma)$, a unique equilibrium exists:

- with constrained credit and $i=0$ for $\pi \in(\beta-1, \underline{\pi})$;

- with constrained credit and $i>0$ for $\pi \in[\underline{\pi}, \hat{\pi}]$;

- with unconstrained credit for $\pi \in(\hat{\pi}, \infty)$. 
2. Suppose $\alpha=1$. If $k^{*}>(1-\sigma) q_{b}^{*}$, there exists a unique equilibrium with unconstrained credit for any $\pi \in(\beta-1, \infty)$. If $k^{*}=(1-\sigma) q_{b}^{*}$, there exists a unique equilibrium with constrained credit and $i>0$ for any $\pi \in(\beta-1, \infty)$. If $k^{*}<(1-\sigma) q_{b}^{*}$, there exists a critical rate $\underline{\pi}^{\prime} \in(\beta-1, \infty)$ such that a unique equilibrium exists:

- with constrained credit and $i=0$ for $\pi \in\left(\beta-1, \underline{\pi}^{\prime}\right)$;

- with constrained credit and $i>0$ for $\pi \in\left[\underline{\pi}^{\prime}, \infty\right)$.

3. Suppose $\alpha>1$. If $k^{*} \geq(1-\sigma) q_{b}^{*}$, there exist two critical rates $\tilde{\pi}^{\prime}>\hat{\pi}^{\prime} \in(\beta, \infty)$ such that given $\lim _{q_{b} \rightarrow 0} u^{\prime}\left(q_{b}\right) q_{b}>k^{*} /(1-\sigma)$, a unique equilibrium exists:

- with unconstrained credit for $\pi \in\left(\beta, \hat{\pi^{\prime}}\right), ;$

- with constrained credit and $i>0$ for $\pi \in\left[\hat{\pi}^{\prime}, \tilde{\pi}^{\prime}\right]$.

For $\pi>\tilde{\pi}^{\prime}$, there exist no equilibrium. If $k^{*}<(1-\sigma) q_{b}^{*}$, there exist two critical values $\tilde{\pi}^{\prime \prime}>$ $\underline{\pi}^{\prime \prime} \in(\beta-1, \infty)$ such that a unique equilibrium exists:

- with constrained credit and $i=0$ for $\pi \in\left(\beta-1, \underline{\pi}^{\prime \prime}\right]$;

- with constrained credit and $i>0$ for $\pi \in\left(\underline{\pi}^{\prime \prime}, \tilde{\pi}^{\prime \prime}\right]$.

For $\pi>\tilde{\pi}^{\prime \prime}$ there exist no equilibrium.

The following proposition summarizes behavior of the level of capital holdings in response to changes in the inflation rate. These responses also depend on the coefficient of risk aversion, $\alpha$, and on the first best level of capital $k^{*}$ relative to $\sigma$ and $q_{b}^{*}$.

Proposition 21 . Suppose $\alpha<1$. If $k^{*} \geq(1-\sigma) q_{b}^{*}$, the level of capital $k$ is constant at the first best $k^{*}$. If $k^{*}<(1-\sigma) q_{b}^{*}, k$ is first increasing, then decreasing and finally constant in the inflation rate.

2. Suppose $\alpha=1$. If $k^{*} \geq(1-\sigma) q_{b}^{*}, k$ is constant at $k^{*}$. If $k^{*}<(1-\sigma) q_{b}^{*}, k$ is first increasing, then constant in the inflation rate.

3. Suppose $\alpha>1$. If $k^{*} \geq(1-\sigma) q_{b}^{*}, k$ is constant and then increasing in the inflation rate. If $k^{*}<(1-\sigma) q_{b}^{*}, k$ is always increasing in the inflation rate.

Essentially, accumulating capital over and above its First Best level is a way for agents to relax their borrowing constraint, when the First Best level itself is not abundant enough to perform fully both its productive and its collateral role. In turn, when capital is above First Best, monetary growth can affect its accumulation, since monetary growth affects the tightness of the borrowing constraint. The particular way in which accumulation of capital is affected by monetary growth - and thus inflation- depends on the elasticity of day-time demand to inflation. Since this is in a one-to-one relationship with the relative risk aversion of agents, we stated our results in terms of the latter, more primitive concept. When relative risk aversion is lower than one, if the first best amount of capital is enough to obtain a loan and buy the first best amount of day-time consumption, the credit constraint does not bind and inflation does not affect capital accumulation. If the first best amount of capital is not enough though, then the inflation rate matters in the following way. When inflation is close to the discount factor, the credit constraint binds and the nominal interest rate is zero. Banks keep voluntary reserves. Capital accumulation increases in the inflation rate. For higher inflation rates the nominal interest rate becomes positive and capital accumulation decreases with inflation. For even higher inflation rates the credit constraint does not bind and capital accumulation is unaffected by the inflation rate. The intuition is as follows. If relative risk aversion is lower than one, the demand for daytime consumption - which is always decreasing in the inflation rate- is more than unit elastic in inflation. If capital is abundant, the credit constraint is never binding, even for very high inflation, agents reduce their demand for the day-time good more than one to one with inflation and thus don't need to accumulate extra capital. When capital is relatively scarce though, when inflation is low - and the interest is zero- they accumulate as much capital as possible to obtain a loan and consume the highest possible amount of day-time goods but as inflation grows they reduce their demand for day-time consumption more than one to one with inflation and this 
reduces their need for loans and thus for capital as collateral. Eventually capital accumulation reverts to its first best level and is unaffected by monetary policy. When relative risk aversion is one, demand is unit elastic in inflation and thus we have that if capital is abundant, agents are credit unconstrained and do not over-accumulate capital, if capital is scarce agents accumulate extra capital until the interest rate is zero, but when the interest rate becomes positive they stop accumulating extra capital since instead of getting bigger loans they reduce consumption one to one with inflation. When relative risk aversion is higher than one, demand is less than unit elastic in inflation, so if capital is abundant, at low inflation rates agents have no use for extra capital, but as inflation grows agents reduce their demand less than one to one with inflation. This induces them to accumulate more and more capital in order to relax a tighter and tighter credit constraint. Eventually the economy reaches a point where such a high level of capital cannot be sustained and the credit equilibrium disappears. When capital is scarce agents start accumulating extra capital even at very low levels of inflation.

\subsection{Discussion}

The main assumptions of the model are limited enforcement of contracts, anonymity and impossibility to monitor of agents and the fact that capital is observable and verifiable. In our framework, they imply that agents can always refuse to work, agents can walk away with whatever output they produced, but their asset can be seized by the bank. Our assumptions about enforcement differ from those in Berentsen, Camera and Waller (2006), who introduce lending and borrowing - but not capital- in a Lagos and Wright (2005) framework. They assume that the bank can either enforce contracts perfectly or it can exclude agents from borrowing and lending for ever should they default once. In our paper enforcement is more limited than in their world. One of the crucial assumptions of the model is that capital cannot be moved. This assumption is adopted in Aruoba and Wright (2003), but not in the related paper by Aruoba, Waller and Wright (2006). These papers are concerned with the neoclassical dicothomy between nominal and real variables and specifically between money growth and capital accumulation. The former induces such a dicothomy assuming that capital cannot be moved and used in the day-time market, while the latter breaks the dicothomy assuming that capital has a cost saving role during day-time production. Our paper has both dicothomous and non-dicothomous regions, while maintaining throughout that capital cannot be moved from the night-time market place. This assumption, while capturing a realistic feature of many assets- especially real estate-, is necessary to exclude the possibility for capital to compete and possibly replace money as a means of exchange. Lagos and Rocheteau (2006) consider a world where capital competes with money as a means of exchange. A further assumption we make is that banks have superior skills in verifying and seizing assets, relative to dispersed individuals- who, we assume, don't have such skills-. This assumption, while realistic and common in the banking literature - see e.g. Diamond and Rajan (2001)- deserves some extra care in our framework. We saw that capital cannot be used as a medium of exchange, since it cannot be moved. However it could be used to guarantee bilateral promises agents may issue when meeting each other during the day, thus making money and bank loans redundant. If agents cannot seize assets, this never happens. It is interesting, though, to know what would it happen if agents themselves could seize assets. Here is an argument - along the lines of Lagos and Rocheteau (2006)- which answers such a question. When the First Best level of capital is enough to conduct trade on the day-time market so as to produce and consume the efficient quantity, then money is not useful and can be beneficially replaced by bilateral promises backed by capital. If the First Best level of capital is not enough, though, agents will over-accumulate it in order to use it as collateral for bilateral loans. In such a situation, trading with money and bank loans can reduce the over-accumulation of capital. This is true, obviously, for the region of the parameters space where over-accumulation doesn't happen. But even when over-accumulation does happen in equilibrium, capital is over-accumulated less in a monetary economy than in a non monetary one, since money allows agents to economize 
on it. Thus, if capital is relatively scarce, there exist a monetary equilibrium with bank loans which dominates the non-monetary equilibrium with bilateral collateralized loans.

\section{Conclusion}

We considered an economy with lending and capital accumulation where capital can serve as collateral for consumption loans. We found scenarios where inflation affects capital accumulation and agents accumulate capital over and above its First Best level.

We believe the current model would be a fruitful framework to address, in future research, the question of the role played by the price of the durable good in explaining the persistence and amplification of monetary shocks.

\section{References}

[1] Aruoba, S. Boragan and Randall Wright (2003), Search, Money and Capital: a Neoclassical Dichotomy, Journal of Money, Credit and Banking, 35(6), pp.1086-1105.

[2] Aruoba, S. Boragan, Christopher Waller and Randall Wright (2006), Money and Capital, mimeo.

[3] Berentsen, Aleksander, Gabriele Camera and Christopher Waller (2006), Money, Credit and Banking, Journal of Economic Theory, forthcoming.

[4] Douglas, W. Diamond, and Raghuram G. Rajan (2001), Liquidity Risk, Liquidity Creation and Financial Fragility: A Theory of Banking, Journal of Political Economy, 109, pp.287327.

[5] Kiyotaki, Nobuhiro and John Moore (1997), Credit Cycles, Journal of Political Economy, 105, pp.211-248.

[6] Lagos, Ricardo and Guillaume Rocheteau (2006), Money and Capital as Competing Media of Exchange, Journal of Economic Theory, forthcoming.

[7] (2005), Inflation, Output, and Welfare, International Economic Review, 46, pp.495-522.

[8] Lagos, Ricardo and Randall Wright (2005), A Unified Framework for Monetary Theory and Policy Analysis, Journal of Political Economy, 113, pp.463-484.

[9] Rocheteau, Guillaume, and Randall Wright (2005), Money in Search Equilibrium, in Competitive Equilibrium, and in Competitive Search Equilibrium, Econometrica, 73, pp.175-202.

\section{Appendix}

\subsection{Proof of Proposition 1}

In the main text we have shown that equations (6), (17), (19), (20), (21), (22), (23), (24), (25), (26) are the equilibrium requirements in our economy. All that remains here is to find a solution $q_{b}, k, q_{s}, x_{b}, x_{s}$, $d,, l, p, \phi>0, i, \mu \geq 0$ to these equations. The equilibrium system can be reduced to the following equations that determine $q_{b}, k, i, \mu$ : 


$$
\begin{gathered}
1=\frac{\beta}{1+\pi}\left[\sigma u^{\prime}\left(q_{b}\right)+(1-\sigma)(1+i)\right] \\
1=\beta\left[\sigma\left(\frac{u^{\prime}\left(q_{b}\right)}{1+i}-1\right)+F^{\prime}(k)\right] \\
{\left[u^{\prime}\left(q_{b}\right)-(1+i)\right]\left[k-\frac{(1-\sigma)(1-\mu)}{\sigma+(1-\sigma)(1-\mu)}(1+i) q_{b}\right]=0 ;} \\
\mu=1-\frac{\sigma k}{(1-\sigma)\left(q_{b}-k\right)} .
\end{gathered}
$$

if and only if $i=0$ and $k<(1-\sigma) q_{b}$, and $\mu=0$ otherwise. To derive these equations, we use equations (17), (19), (20), (21), (22), (23), (26). In what follows, we first show the existence and uniqueness of $q_{b}, k>0, i, \mu \geq 0$ to equations (27) - (30). There are six cases, depending on the coefficient of relative risk aversion, denoted $\alpha \equiv-u^{\prime \prime}\left(q_{b}\right) q_{b} / u^{\prime}\left(q_{b}\right)$, and on the efficient level of capital $k^{*}=F^{\prime-1}(1 / \beta)$ relative to $\sigma$ and $q_{b}^{*}=u^{\prime-1}(1)$. We examine each case in separation below. Given this solution, the equilibrium solution of other variables $q_{s}, x_{b}, x_{s}, d, l, p, \phi>0$ is then identified by using equations (6), (24), (25), (26). This solution satisfies equations (6), (17), (19), (20), (21), (22), (23), (24), ((25)), (26) and so describes equilibrium.

Case 1-A: $\quad \alpha<1$ and $k^{*}>(1-\sigma) q_{b}^{*}$. For any $1+\pi \in(\beta, \infty)$, an equilibrium is without binding credit-constraint, exists, is unique and satisfies: $q_{b} \in\left(0, q_{b}^{*}\right), k=k^{*}, i \in(0, \infty), \mu=0, x \in(0, \infty)$, $d \in(0, \infty), l \in(0, \infty), p \in(0, \infty), \phi \in(0, \infty), q_{s} \in\left(0, q_{s}^{*}\right)$.

Proof of Case 1-A. First of all, note that because equilibrium requires $u^{\prime}(q) \geq 1+i$, equations (27),(28) imply that: $q_{b} \rightarrow q_{b}^{*}, i \rightarrow 0, k=k^{*}$ as $1+\pi \rightarrow \beta$. Given $k^{*}>(1-\sigma) q_{b}^{*}$, this further implies that, an equilibrium, if it exists, must be without binding credit-constraint (i.e., $k>(1-\sigma)(1+i) q_{b}$ holds) and $\mu=0$ for $1+\pi$ close to $\beta$, in which case $q_{b}, i, k$ are determined by

$$
\begin{gathered}
u^{\prime}\left(q_{b}\right)=\frac{1+\pi}{\beta}, \\
1+i=\frac{1+\pi}{\beta}, \\
F^{\prime}(k)=\frac{1}{\beta} .
\end{gathered}
$$

A solution to these equations exists and is unique, given our assumptions on $u(\cdot)$ and $f(\cdot)$.

Second, observe that $u^{\prime}\left(q_{b}\right) q_{b}$ is strictly increasing in $q_{b}$ when $\alpha \equiv-u^{\prime \prime}(\cdot) q_{b} / u^{\prime}(\cdot)<1$ and that $q_{b}$ is strictly decreasing in $1+\pi$ when equation (31) holds. So, when the credit constraint is not binding, the total amount of debt payment $(1-\sigma)(1+i) q_{b}=(1-\sigma) u^{\prime}\left(q_{b}\right) q_{b}$ takes a maximum $(1-\sigma) q_{b}^{*}$ at $1+\pi=\beta$ that satisfies $k^{*}>(1-\sigma) q_{b}^{*}$. Because $k$ is determined independently of $1+\pi$, this implies that $k=k^{*}>(1-\sigma) q_{b}^{*} \geq(1-\sigma) u^{\prime}\left(q_{b}\right) q_{b}$ hold for any $1+\pi \in(\beta, \infty)$ and so $\mu=0$ and $q_{b}, i, k>0$ are determined by equations (31)-(33), which exist and are unique. Given that solution $q_{b}>0$, noting equilibrium satisfies $m^{\prime}=M_{+1}=(1+\tau) M=d, \phi=1 / p, l=(1-\sigma) p q_{b},(1-\sigma) d=\sigma l$ and $(1-\sigma) q_{s}=\sigma q_{b}$, implies that $\phi, p, d, l, q_{s}>0$ exists and is unique.

Finally, given these equilibrium values equation (6) gives:

$$
\begin{aligned}
x_{b} & =F(k)-k-\phi\left(m^{\prime}-m_{1}\right)+\phi(1+i)(d-l) \\
& =F(k)-k-\sigma q_{b}-(1-\sigma) u^{\prime}\left(q_{b}\right) q_{b}> \\
& >F\left(k^{*}\right)-k^{*}-q_{b}^{*}>0 .
\end{aligned}
$$

for a buyer where the last two inequalities follow from $k=k^{*}, q_{b}^{*}>u^{\prime}\left(q_{b}\right) q_{b}$, and our assumption that $F\left(k^{*}\right)>k^{*}+q_{b}^{*}$. Given this, the corresponding value for a seller must satisfy $x_{s}>0$, which can be identified by equation (25). This completes the proof of Case 1-A. 
Case 1-B: $\alpha<1$ and $k^{*} \leq(1-\sigma) q_{b}^{*}$. For $1+\pi \in[\beta, \infty)$ an equilibrium exists, is unique and implies, given $\lim _{q_{b} \rightarrow 0} u^{\prime}\left(q_{b}\right) q_{b}<k^{*} /(1-\sigma)$, that the credit constraint is not binding for $1+\pi \in$ $(1+\hat{\pi}, \infty)$ whereas the credit constraint is binding with $i=0$ and $\mu>0$ for $1+\pi \in(\beta, 1+\underline{\pi})$, and with $i>0$ and $\mu=0$ for $1+\pi \in[1+\underline{\pi}, 1+\hat{\pi}]$, where $1+\hat{\pi}>1+\underline{\pi} \in(\beta, \infty)$.

Proof of Case 1-B. Observe first from equations (27),(28) that $q_{b} \rightarrow 0,1+i \rightarrow \infty$ in the limit as $1+\pi \rightarrow \infty$, and hence from equations $(28),(29)$ that $u^{\prime}\left(q_{b}\right) /(1+i) \rightarrow 1$ as $1+\pi \rightarrow \infty$ given $\lim _{q_{b} \rightarrow 0} u^{\prime}\left(q_{b}\right) q_{b}<k^{*} /(1-\sigma)$. This implies that if an equilibrium exists, then it must be without binding credit-constraint for a sufficiently large $1+\pi$. Hence, given $k^{*}=k \leq(1-\sigma) q_{b}^{*}=(1-\sigma) u^{\prime}\left(q_{b}\right) q_{b}$ at $1+\pi=\beta$ and $u^{\prime}\left(q_{b}\right) q_{b}$ is strictly decreasing in $1+\pi$ (when the constraint is not binding and $\alpha<1$ ), there exists a unique cutoff value $1+\hat{\pi} \in(\beta, \infty)$ that solves

$$
k^{*}=k=(1-\sigma) u^{\prime}\left(q_{b}\right) q_{b} .
$$

That is, an equilibrium is without binding credit-constraint for $1+\pi>1+\hat{\pi}$ and is with binding credit-constraint for $1+\pi \leq 1+\hat{\pi}$. As shown in the proof of Case $1-\mathrm{A}, \mu=0$ and $q_{b}, k, i>0$ are a unique solution to equations (31)-(33) when the constraint is not binding, and so for $1+\pi \in(1+\hat{\pi}, \infty)$ an equilibrium exists and is unique given $F\left(k^{*}\right)>k^{*}+q_{b}^{*}$.

For $1+\pi \leq 1+\widehat{\pi}$, given $k^{*} \leq(1-\sigma) q^{*}$ there is a possibility that $i=0$ and $\mu>0$. Indeed, when $1+\pi \rightarrow \beta$, equations (27)-(30) imply $q \rightarrow q^{*}, k \rightarrow k^{*}, i \rightarrow 0, \mu \rightarrow \mu^{*} \equiv 1-\sigma k^{*} /(1-\sigma)\left(q_{b}^{*}-k^{*}\right)>0$. Hence, for $1+\pi$ close to $\beta$, if an equilibrium exists then it must satisfy $i=0$ and $q_{b}, k, \mu$ are given by

$$
\begin{gathered}
u^{\prime}\left(q_{b}\right)=\frac{(1+\pi)-\beta(1-\sigma)}{\beta \sigma}, \\
F^{\prime}(k)=\frac{1-[(1+\pi)-\beta]}{\beta}, \\
\mu=1-\frac{\sigma k}{(1-\sigma)\left(q_{b}-k\right)} .
\end{gathered}
$$

For $1+\pi \in(\beta, 1+\underline{\pi}]$, a solution $q_{b} \in\left[\underline{q}_{b}, q_{b}^{*}\right), k \in\left(k^{*}, \underline{k}\right], \mu \in\left[0, \mu^{*}\right)$ to equations (35)-(37) exists and is unique, where $1+\underline{\pi} \in(\beta, 1+\overline{\hat{\pi}})$ is a unique solution to $\underline{k}=(1-\sigma) \underline{q}$ (which leads to $\mu=0)$. Given that solution $q_{b}>0$ and $\mu \geq 0$, the other equilibrium values are uniquely identified by $m^{\prime}=d>0, \sigma l=(1-\mu)(1-\sigma) d>0,(1-\sigma)(1-\mu) p q_{b}=l\{\sigma+(1-\sigma)(1-\mu)\}>0, \phi=1 / p>0$, $(1-\sigma) q_{s}=\sigma q_{b}>0$ and

$$
x_{b}=F(k)-k-\phi m^{\prime}-\phi(1+i) l=F(k)-k-q_{b}>0 .
$$

which follows from $k^{*}<k \leq(1-\sigma) q_{b}^{*}$ and our assumption that $F\left(k^{*}\right)>q_{b}^{*}+(1-\sigma) q_{b}^{*}$.

Note above that $\mu$ is strictly decreasing in $1+\pi$ and takes the minimum $\mu=0$ at $1+\underline{\pi}$. This means, if an equilibrium exists for $1+\pi>1+\underline{\pi}$, then it must satisfy $\mu=0$ and thereby $i>0$ (whenever $\left.k=(1-\sigma)(1+i) q_{b}\right)$. Hence, for $1+\pi \in(1+\underline{\pi}, 1+\hat{\pi})$ define:

$\Phi\left(q_{b}, 1+\pi\right) \equiv\left(\frac{1+\pi}{\beta}-\sigma u^{\prime}\left(q_{b}\right)\right)\left(1+\beta-\beta F^{\prime}\left[\left(\frac{1+\pi}{\beta}-\sigma u^{\prime}\left(q_{b}\right)\right) q_{b}\right]\right)-(1-\sigma)(1+\pi)=0$

using equations (27),(28). Observe that for $1+\pi \in(1+\underline{\pi}, 1+\hat{\pi}), \Phi(\cdot)$ satisfies: $\Phi\left(\hat{q}_{b} ; 1+\pi\right)>0$ where $\hat{q}_{b} \in\left(0, q_{b}^{*}\right)$ is given by $u^{\prime}\left(\hat{q}_{b}\right)=(1+\pi) / \beta ; \Phi\left(\underline{q}_{b}, 1+\pi\right)<0$ where $\underline{q}_{b}$ is given by $u^{\prime}\left(\underline{q}_{b}\right)=$ $(1+\pi-\beta(1-\sigma)) / \beta \sigma$, and where $1+\underline{\pi} \in(\beta, 1+\hat{\pi})$ is a unique solution to $1+\beta-\beta F^{\prime}(\underline{k})=\underline{1}+\underline{\pi}$ and $\underline{k}=(1-\sigma) \underline{q}_{b}$. Therefore, because $\Phi(\cdot)$ is continuous in $q_{b}$ and $\partial \Phi(\cdot) / \partial q_{b}>0$, there exists a unique solution $q_{b} \in\left(\hat{q}_{b}, \underline{q}_{b}\right)$ that satisfies $\Phi(\cdot)=0$ for $1+\pi \in(1+\underline{\pi}, 1+\hat{\pi})$. Given $q_{b}>0$ determined above, $k, i>0$ solve for

$$
\begin{gathered}
k=\left(\frac{1+\pi}{\beta}-\sigma u^{\prime}\left(q_{b}\right)\right) q_{b}, \\
1+i=\frac{k}{(1-\sigma) q_{b}} .
\end{gathered}
$$


which are obtained by applying $\mu=0$ to equations (27),(29). Note $k \in\left(k^{*}, \underline{k}\right)$ and $i>0$ in equations (39),(40) are respectively strictly increasing in $q_{b} \in\left(\hat{q}_{b}, \underline{q}_{b}\right)$, hence the solutions are unique. The other equilibrium values are uniquely identified by the same procedure as before, except that

$$
x_{b}=F(k)-k-\phi m^{\prime}-\phi(1+i) l=F(k)-k-\sigma q_{b}-k>0,
$$

follows from the fact that $k^{*}<k<(1-\sigma) q_{b}^{*}$ and our assumption that $F\left(k^{*}\right)>q_{b}^{*}+(1-\sigma) q_{b}^{*}$. This completes the proof of Case 1-B.

Case 2-A: $\alpha=1$ and $k^{*}>(1-\sigma) q_{b}^{*}$. For any $1+\pi \in(\beta, \infty)$, an equilibrium is without binding credit-constraint, exists, and is unique.

Proof of Case 2-A. The claim can be shown as in the proof of Case 1-A. That is, noting that equations (27),(28) yield $q_{b} \rightarrow q_{b}^{*}, i \rightarrow 0, k \rightarrow k^{*}$ as $1+\pi \rightarrow \beta$, implies given $k^{*}>(1-\sigma) q_{b}^{*}$, an equilibrium, if it exists, must be without binding credit-constraint (i.e., $k>(1-\sigma)(1+i) q_{b}$ holds) and $\mu=0$ for $1+\pi$ close to $\beta$, in which case $q_{b}, i, k$ are determined by equations (31)-(33). Further, $\alpha=1$ implies $u^{\prime}\left(q_{b}\right) q_{b}$ is constant with respect to $q_{b}$, and so

$$
k^{*}=k>(1-\sigma) q_{b}^{*}=(1-\sigma) u^{\prime}\left(q_{b}\right) q_{b},
$$

for any $1+\pi \in(\beta, \infty)$. Hence, for any $1+\pi \in(\beta, \infty)$ the credit constraint is not binding and $\mu=0$ and $q_{b}, i, k>0$ are given uniquely by equations (31)-(33). Identifying the other equilibrium variables, which exist and are unique, follows the same procedure as before where in particular $x>0$ requires $F\left(k^{*}\right)>q_{b}^{*}+k^{*}$. This completes the proof of Case 2-A.

Case 2-B: $\alpha=1$ and $k^{*} \leq(1-\sigma) q_{b}^{*}$. When $k^{*}=(1-\sigma) q_{b}^{*}$, an equilibrium is with binding credit-constraint, exists, is unique and satisfies $\mu=0$ and $i>0$ for all $1+\pi \in(\beta, \infty)$. When $k^{*}<(1-\sigma) q_{b}^{*}$, an equilibrium is with binding credit-constraint, exists, is unique and satisfies $\mu>0$ and $i=0$ for $1+\pi \in\left(\beta, 1+\underline{\pi}^{\prime}\right)$, and $\mu=0$ and $i>0$ for $1+\pi \in\left[1+\underline{\pi}^{\prime}, \infty\right)$, where $1+\underline{\pi}^{\prime} \in(\beta, \infty)$.

Proof of Case 2-B. When $k^{*}=(1-\sigma) q_{b}^{*}$ and $\alpha=1$, note that an equilibrium, if it exists, implies $\mu=0$ and is with just binding credit-constraint, i.e., both $u^{\prime}\left(q_{b}\right)=1+i$ and $k=(1-\sigma)(1+i) q_{b}$ hold for all $1+\pi \in(\beta, \infty)$. Hence, $q_{b}, i, k>0$ satisfies equations (31)-(33) and so an equilibrium exists and is unique given $F\left(k^{*}\right)>q_{b}^{*}+k^{*}$.

When $k^{*}<(1-\sigma) q_{b}^{*}$ and $\alpha=1$, an equilibrium must be with binding credit-constraint for any $1+\pi \in(\beta, \infty)$. Further, as in Case $1-\mathrm{B}$, there exists a unique cutoff value $1+\underline{\pi}^{\prime} \in(\beta, \infty)$ such that equilibrium implies $\mu>0$ and $i=0$ for $1+\pi \in\left(\beta, 1+\underline{\pi}^{\prime}\right)$, and $\mu=0$ and $i>0$ for $1+\pi \in\left[1+\underline{\pi}^{\prime}, \infty\right)$. Precisely, $q_{b} \in\left[\underline{q}_{b}^{\prime}, q_{b}^{*}\right), k \in\left(k^{*}, \underline{k}^{\prime}\right], \mu \in\left[0, \mu^{*}\right)$ are uniquely determined by equations (35)-(37) for $1+\pi \in\left(\beta, 1+\underline{\pi}^{\prime}\right]$, while $q_{b} \in\left(0, \underline{q}_{b}^{\prime}\right), k=\underline{k}^{\prime}, i \in(0, \infty)$ are uniquely determined by equations (38)-(40) for $1+\pi \in\left(1+\underline{\pi}^{\prime}, 1+\bar{\pi}\right)$, where $1+\underline{\pi}^{\prime}$ gives $\underline{k}^{\prime}=(1-\sigma) \underline{q}_{b}^{\prime}$ and $i=0$.

Finally, for $1+\pi \in\left(\beta, 1+\underline{\pi}^{\prime}\right]$ we have $k^{*}<k<(1-\sigma) q_{b}^{*}$ and so $x>0$ given $F\left(k^{*}\right)>$ $q_{b}^{*}+(1-\sigma) q_{b}^{*}$. For $1+\pi>1+\underline{\pi}^{\prime}$, because $k=\underline{k}^{\prime}>k^{*}$ (see the proof of Proposition 2 ), $x>0$ is guaranteed for any $1+\pi \in\left(1+\underline{\pi}^{\prime}, \infty\right)$ given $F\left(k^{*}\right)>q_{b}^{*}+(1-\sigma) q_{b}^{*}$. Hence, the equilibrium exists and is unique. This completes the proof of Case 2-B.

Case 3-A: $\alpha>1$ and $k^{*}>(1-\sigma) q_{b}^{*}$. For $1+\pi \in\left(\beta, 1+\tilde{\pi}^{\prime}\right)$ an equilibrium exists, is unique and implies, given $\lim _{q_{b} \rightarrow 0} u^{\prime}\left(q_{b}\right) q_{b}>k^{*} /(1-\sigma)$, that the credit constraint is not binding for $1+\pi \in$ $\left(\beta, 1+\hat{\pi}^{\prime}\right)$ whereas the credit constraint is binding with $i>0$ and $\mu=0$ for $1+\pi \in\left[1+\hat{\pi}^{\prime}, 1+\tilde{\pi}^{\prime}\right)$, where $1+\tilde{\pi}^{\prime}>1+\hat{\pi}^{\prime} \in(\beta, \infty)$.

Proof of Case 3-A. Observe first from equations (27),(28) that $q_{b} \rightarrow 0,1+i \rightarrow \infty$ in the limit as $1+\pi \rightarrow \infty$. Assuming $\lim _{q_{b} \rightarrow 0} u^{\prime}\left(q_{b}\right) q_{b}>k^{*} /(1-\sigma)$ implies that if an equilibrium exists, then it must be with binding credit-constraint for a sufficiently large $1+\pi$. Hence, given $k=k^{*}>(1-\sigma) q_{b}^{*}=$ $(1-\sigma) u^{\prime}\left(q_{b}\right) q_{b}$ as $1+\pi \rightarrow \beta$ and $u^{\prime}\left(q_{b}\right) q_{b}$ is strictly increasing in $1+\pi$ (when the constraint is not binding and $\alpha>1)$, there exists a unique cutoff value $1+\hat{\pi}^{\prime} \in(\beta, \infty)$ that solves equation (34). 
That is, an equilibrium is without binding credit-constraint for $1+\pi<1+\hat{\pi}^{\prime}$ and is with binding credit-constraint for $1+\pi \geq 1+\hat{\pi}^{\prime}$. As shown in the proof of Case $1-\mathrm{A}, \mu=0$ and $q_{b}, i, k>0$ are a unique solution to equations (31)-(33) when the constraint is not binding, and so for $1+\pi \in\left(\beta, 1+\hat{\pi}^{\prime}\right)$ an equilibrium exists and is unique given $F\left(k^{*}\right)>k^{*}+q_{b}^{*}$.

For $1+\pi \geq 1+\widehat{\pi}^{\prime}$, notice $q_{b}$ must satisfy equation (38) because $\mu=0$. Observe that for $1+\pi \in$ $\left[1+\hat{\pi}^{\prime}, \infty\right), \Phi(\cdot)$ satisfies: $\Phi\left(\hat{q}_{b}^{\prime} ; 1+\pi\right)>0$ where $\hat{q}_{b}^{\prime} \in\left(0, q_{b}^{*}\right)$ is given by $u^{\prime}\left(\hat{q}_{b}^{\prime}\right)=(1+\pi) / \beta$; $\Phi\left(\bar{q}_{b}^{\prime}, 1+\pi\right)<0$ where $\bar{q}_{b}^{\prime} \in\left(\beta, \hat{q}_{b}^{\prime}\right)$ is given by $u^{\prime}\left(\bar{q}_{b}^{\prime}\right)=(1+\pi) / \sigma \beta$. Therefore, because $\Phi(\cdot)$ is continuous in $q_{b}$ and $\partial \Phi(\cdot) / \partial q_{b}>0$, there exists a unique solution $q_{b} \in\left(\bar{q}_{b}^{\prime}, \hat{q}_{b}^{\prime}\right)$ that satisfies $\Phi(\cdot)=0$ for $1+\pi \in[1+\hat{\pi}, \infty)$. Given this solution, $k, i>0$ are uniquely determined by equations (39),(40) respectively.

To guarantee $x>0$ requires an extra care in this case, since $k \geq k^{*}>(1-\sigma) q_{b}^{*}$ for $1+\pi \in$ $\left[1+\hat{\pi}^{\prime}, \infty\right)$ (see the proof of Proposition 2). Note, however, that at $1+\pi=1+\hat{\pi}^{\prime}$, we have $q_{b}=\hat{q}_{b}^{\prime}<q_{b}^{*}$ and $k=k^{*}=(1-\sigma) \hat{q}_{b}^{\prime}$, hence

$$
x=F\left(k^{*}\right)-k^{*}-\sigma \hat{q}_{b}^{\prime}-k^{*}=F\left(k^{*}\right)-k^{*}-\hat{q}_{b}^{\prime}>F\left(k^{*}\right)-k^{*}-q_{b}^{*}>0,
$$

at $1+\pi=1+\hat{\pi}^{\prime}$ given $F\left(k^{*}\right)>k^{*}+q_{b}^{*}$. Hence, there exists some $1+\tilde{\pi}^{\prime} \in\left(1+\hat{\pi}^{\prime}, \infty\right)$ such that $x>0$ and hence the existence and uniqueness of the equilibrium are guaranteed for $1+\pi \in\left[1+\hat{\pi}^{\prime}, \infty\right)$. This completes the proof of Case 3-A.

Case 3-B: $\alpha>1$ and $k^{*} \leq(1-\sigma) q_{b}^{*}$. For $1+\pi \in\left(\beta, 1+\tilde{\pi}^{\prime \prime}\right]$ an equilibrium is with binding credit-constraint, exists, is unique and satisfies $i=0, \mu>0$ for $1+\pi \in\left(\beta, 1+\underline{\pi}^{\prime \prime}\right)$ and $i>0$ and $\mu=0$ for $1+\pi \in\left[1+\underline{\pi}^{\prime \prime}, 1+\tilde{\pi}^{\prime \prime}\right)$, where $1+\tilde{\pi}^{\prime \prime}>1+\underline{\pi}^{\prime \prime} \in(\beta, \infty)$.

Proof of Case 3-B. Note first that given $\alpha>1$ and $k^{*} \leq(1-\sigma) q_{b}^{*}$ an equilibrium, if it exists, must be with binding credit-constraint. Observe that when $1+\pi \rightarrow \beta$, equations (27)-(30) imply $q \rightarrow q^{*}$, $k \rightarrow k^{*}, i \rightarrow 0, \mu \rightarrow \mu^{*} \equiv 1-\sigma k^{*} /(1-\sigma)\left(q_{b}^{*}-k^{*}\right)>0$. Hence, for $1+\pi$ close to $\beta$, if an equilibrium exists then it must satisfy $i=0$ and $q_{b}, k, \mu$ are given by equations (35)-(37). As shown in the proof of Case 1-B, a solution $q_{b} \in\left[\underline{q}_{b}^{\prime \prime}, q_{b}^{*}\right), k \in\left(k^{*}, \underline{k}^{\prime \prime}\right], \mu \in\left[0, \mu^{*}\right)$ to equations (35)-(37) exists and is unique for $1+\pi \in\left(\beta, 1+\underline{\pi}^{\prime \prime}\right)$, where $1+\underline{\pi}^{\prime \prime} \in(\beta, \infty)$ is a unique solution to $\underline{k}^{\prime \prime}=(1-\sigma) \underline{q}_{b}^{\prime \prime}$ (which leads to $\mu=0)$.

For $1+\pi \in\left[1+\underline{\pi}^{\prime \prime}, 1+\infty\right)$, we must have $\mu=0$, and $q_{b} \in\left(0, \underline{q}_{b}^{\prime \prime}\right), k \in\left(\underline{k}^{\prime \prime}, \infty\right), i \in(0, \infty)$ are unique solution to equations (38)-(40), where $1+\underline{\pi}^{\prime \prime}$ gives $\underline{k}^{\prime \prime}=(1-\sigma) \underline{q}_{b}^{\prime \prime}$ and $i=0$. Finally, $x>0$ can be guaranteed for $1+\pi \in\left(1+\underline{\pi}^{\prime \prime}, 1+\tilde{\pi}^{\prime \prime}\right]$ given $F\left(k^{*}\right)>q_{b}^{*}+(1-\sigma) q_{b}^{*}$ where $1+\pi=1+\tilde{\pi}^{\prime \prime}>1+\underline{\pi}^{\prime \prime}$ yields $k=(1-\sigma) q_{b}^{*}$, and the equilibrium exists and is unique. This completes the proof of Case 3 -B.

\subsection{Proof of Proposition 2}

When the credit constraint is not binding, equation (33) determines $k=k^{*}$ which is independent of $1+\pi$. When the credit constraint is binding with $i=0$ and $\mu>0$, equation (36) determines $k>k^{*}$ which is strictly increasing in $1+\pi>\beta$. When the credit constraint is binding with $i>0$ and $\mu=0$, equation (39) determines $k \geq k_{*}$, given $q_{b}>0$ satisfies equation (38). In this case, noting that

$$
\frac{d q_{b}}{d(1+\pi)}=\frac{-\left(\frac{1+\pi}{\beta}-\sigma u^{\prime}(\cdot)\right)^{2} F^{\prime \prime}(\cdot) q_{b}+\sigma(1-\sigma) u^{\prime}(\cdot)}{\sigma(1-\sigma)(1+\pi) u^{\prime \prime}(\cdot)+\beta\left(\frac{1+\pi}{\beta}-\sigma u^{\prime}(\cdot)\right)^{2} F^{\prime \prime}(\cdot)\left(\frac{1+\pi}{\beta}-\sigma\left(u^{\prime}(\cdot)+u^{\prime \prime}(\cdot) q_{b}\right)\right)}<0
$$

gives:

$$
\begin{aligned}
\frac{d k}{d(1+\pi)} & =\frac{q_{b}}{\beta}+\left(\frac{k}{q_{b}}-\sigma u^{\prime \prime}(\cdot) q_{b}\right) \frac{d q_{b}}{d(1+\pi)} \\
& =\frac{\sigma(1-\sigma) \frac{k}{q_{b}} u^{\prime}(\cdot)(1-\alpha)}{\sigma(1-\sigma)(1+\pi) u^{\prime \prime}(\cdot)+\beta\left(\frac{k}{q_{b}}\right)^{2} F^{\prime \prime}(\cdot)\left(\frac{k}{q_{b}}-\sigma u^{\prime \prime}(\cdot) q_{b}\right)} \gtreqless 0 \quad \text { if } \quad \alpha \gtreqless 1 .
\end{aligned}
$$

